\title{
Sciendo
}

\section{A System Dynamics Approach to Decision- making Tools in Farm Tourism Development}

\author{
Maja Žibert \\ Faculty of Agriculture and Life Sciences, University of Maribor, Slovenia \\ Črtomir Rozman \\ Faculty of Agriculture and Life Sciences, University of Maribor, Slovenia \\ Andrej Škraba \\ Faculty of Organizational Sciences, University of Maribor, Slovenia \\ Boris Prevolšek \\ Faculty of Tourism, University of Maribor, Slovenia
}

\begin{abstract}
Background: Besides visiting the main tourist attractions in Slovenia, many tourists want to spend their free time in the countryside as well, but the number of farming establishments in Slovenia diminished distinctly in the last years. Objectives: This paper aims to develop a system dynamics model, with the goal to analyse dynamics of the diversification of agricultural holdings into farm tourism activities in Slovenia. Methods/Approach: A system dynamics methodology was chosen to model the diversification in farm tourism. First, we present a basic concept of a system dynamics model with a causal loop diagram. Further, a system dynamics model with different scenarios is presented. Results: The main feedback loops were identified, and the simulation model was used to analyse different simulation scenarios of the transition of farming establishments into farm tourism facilities. Conclusions: The model provides the answers to the strategic questions about the dynamics of transfer into tourist farms, using several simulation scenarios. The transition mainly relies on subsidies, promotion of diversification and the growth of rural tourism, which provides a relevant direction for the development of future incentives.
\end{abstract}

Keywords: farm tourism, rural tourism, modelling, system dynamics, causal loop diagram, simulation

JEL classification: Q13

Paper type: Case Study

Received: Jan 31, 2020

Accepted: Jul 6. 2020

Citation: Žibert, M., Rozman, Č., Škraba, A., Prevolšek, B. (2020), "A System Dynamics Approach to Decision-making Tools in Farm Tourism Development", Business Systems Research, Vol. 11, No. 2, pp. 132-148.

DOI: 10.2478/bsrj-2020-0020

\section{Introduction}

Rural tourism has grown in many parts of the world in the last few decades, including Slovenia. In adition, rural tourism allows the development of the countryside, which is 
increalisngly important in the era of growing urbanization. Countries are urgently aiming to find the ways on how to incite economic activitiy in the rural areas, and rural tourism is gaining popularity as one of the most important tools in that endaveour. However, various factors impacts the transitioning of rural areas to the tourism attractive destinations. Bontkes \& van Keulen (2003) defined different factors that affect mainly the socio-economic conditions of rural areas. Through his research, Sharpley (2002) emphasized that low income, relatively low demand, and a lack of skills to develop activities affect the development of rural tourism. Studies showed that tourism as a non-agricultural activity on the farm does not represent only economic benefits. Non-economic benefits are also important (Tew \& Barbieri, 2012). Ollenburg and Buckley, (2007), Barbieri, (2010), Jaafar et al. (2015), Cuncha et al. (2018) and Park et al. (2015) address the importance of marketing opportunities, family connections, and personal pursuits as the most common non-economic benefits of farm tourism.

Many scientists have solved problems related to the development of agriculture and tourism by using different models of system dynamics. Sedarati (2015) proves with his study that the use of the method of system dynamics in tourism is very widespread. Through the research, he found as much as 369 articles that are connected with applying the system dynamics in tourism indirectly or even directly. Several examples will be described. According to Johnson et al. (2008), a model for understanding the ecological, agronomic economic and social dimensions of rural regions has been developed. In their article, Lazanski \& Kljajić (2006) described important contributions in the development of models of system dynamics that are bound with the field of tourism. Jakulin (2016) discusses the usage of system dynamics in the area of tourism.

The goal of our work is to boost the development of rural areas into rural tourism destinations by using system dynamics modelling, with the focus to the diversification, where agricultural holding extend its basic activities. In addition to the studies mentioned earlier, numerous of researchers (e. g. Bastan et al., 2018; Blumberga et al., 2018; Rozman et al., 2013) already used such types of dynamics, and in our work we extend their previou research.

The subject of the research are the main factors that influence the diversification of the agricultural holdings into tourism as the non-agricultural activity. This paper aims to analyze, utilizing systems system dynamics, the main variables and their causal relationships in the system structure, presenting the diversification of the agricultural holding into farm tourism. The case study of Slovenia has been used in order to explore different scenarios for farm tourism development.

\section{Background}

Farm tourism is not a new phenomenon (Busby \& Rendle, 2000). It is a form of countryside tourism which dates back a century in some destinations (Dernoi, 1983). The developmental trends show that more supplementary activities are registered within farming establishments every year. Their common denominator is tourism. It is the consequence of the increasing number of tourists, i.e. lodgings in the country. In 2018, Slovenia recorded 5.93 millions of tourists' arrivals and 15.96 millions of lodgings of the tourists. A part of them resides in tourist farms too. A rich history of the development of tourism in the countryside is recorded in Germany (Oppermann, 1996) and Austria. State policies are positively oriented towards the development of tourist facilities in the countryside with subsidies and programs of development also in Italy (Giaccio et al., 2018) and France (Bel et al., 2015). 
The number of farms in Slovenia is decreasing. Figure 1 presents the number of Farms in Slovenia from 2003 to 2016 (SORS, 2020). The important factor that influences this trend is farm income, which can be improved by diversification. That is why nowadays more and more agricultural holdings decide on developing marketoriented multi-function farming.

Figure 1

Number of Farms in Slovenia from 2003 to 2016

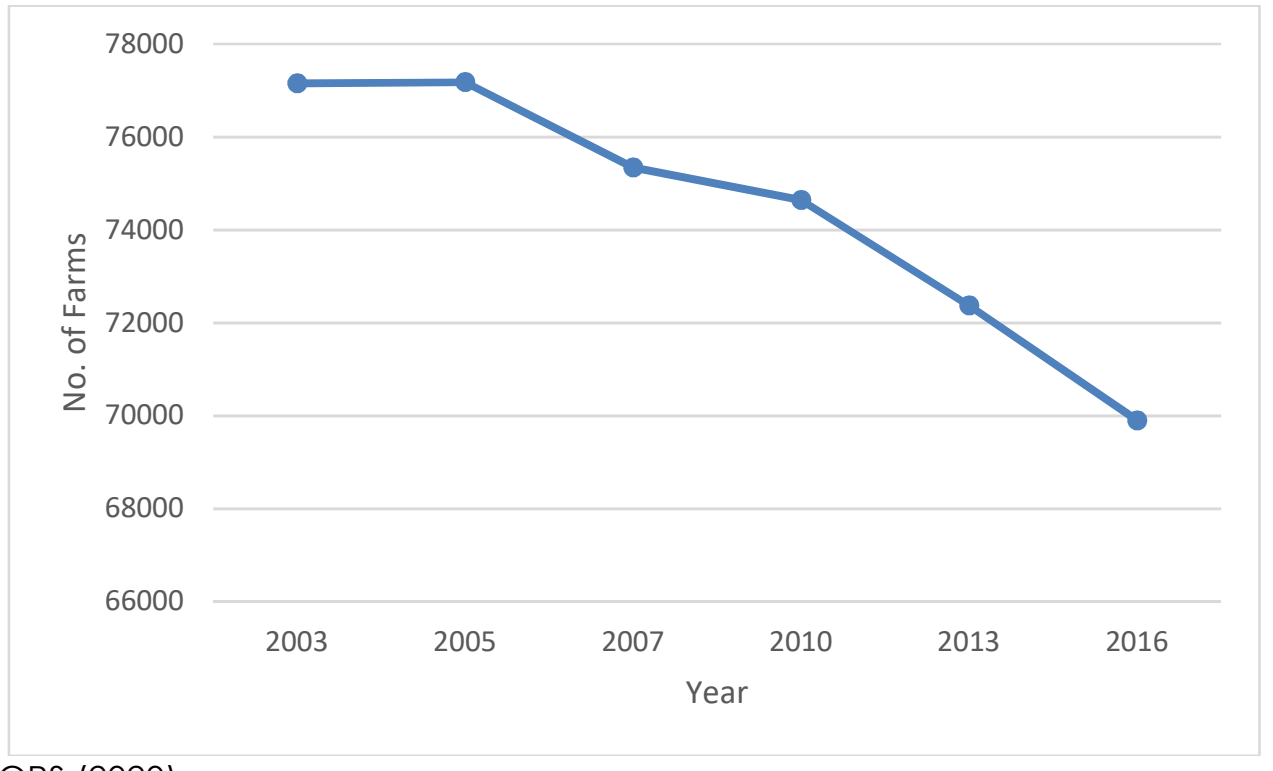

Source: SORS (2020)

All manners of increasing the financial and social stability by gaining income from various sources can be denominated with a common designation "diversification". The predominant economic incentive for the diversification of agricultural holding is the expected increased income. This action, however, does not influence positively only a farming establishment but also offers numerous advantages for the broader region: the quality of life in the countryside (to improve the quality of life is also one of a strategic priority for the European Union), culture, tradition, and, last but not least, employment. Due to all the specifics of the agrarian structures according to Groot et al. (2009) these are mountainous and diverse terrain, the high proportion of karst areas) and lowering the factor incomes per employee in the agriculture (SORS, 2017), the farmers have to think hard about all the factors, not only economic ones, when they think about the step of diversification, especially if an investment would require more significant financial input. In the case of farm tourism as a method of diversification, thus, in addition to economic factors, neither environmental nor social nor socio-cultural factors are negligible (Žibert et al., 2020).

Not all farming establishments are appropriate for a step of this type of diversification. Žibert et al. (2020) researched the attributes of farming establishments for diversification to non-agricultural industries. Sharpley (2002) addresses the importance of long-term financial-technical aids and subsidies when developing farm tourism. Arroyo et al. (2013), Kheiri and Nasihatkon (2016) and Su et al. (2019) also addressed the importance of support services in their works. Muresan et al. (2016), Sharpley and Vass (2006) and Xue et al. (2017) study social context of the farmer's attitude in connection with the diversification of the primary activity in tourism. 
The development of supplementary activities at farm establishment related to tourism bears different advantages and disadvantages. That is why there exists a clear tendency of the use of modern supports in decision-making by which the proper directives can be ensured before bigger investment and activities affecting the environment. Using system dynamics, we can test different alternatives over time.

\section{System dynamics methodology}

Sterman (2000) says that systems thinking is necessary for efficient decision-making. Richmond (1993) speaks about systems thinking as about a multidimensional system where:

- We can think with models, which mean the ability to build a model and transfer the acquired knowledge into a real circumstance.

- We speak about dynamic thinking which enables anticipation of future behaviour of systems with all the delays, fluctuations, and feedback loops.

- We can understand a system as interrelated thinking where a single cause does not mean a single consequence. Consequences depend on a multitude of indirect influences.

- The system management - we understand the dimension of systems thinking as the most pragmatic component.

- Systems thinking and system dynamics observe the same types of problems.

Contrary to the systems thinking, the system dynamics enables us - utilizing computer simulations of the models - a depiction of the behaviour of the real system when testing the effects of alternative decisions through time (Brailsford et al., 2014).

Forrester (1994) described the methodology of system dynamics by which we have followed in this research.

The idea of such modelling is based on the presumptions that every real system, as well as business systems, can be described by a whole of equations which are interconnected (Rozman et al., 2013; Rozman, et. al., 2015). Meanwhile, Sterman (2000) discussed modelling similarly in his work and described it as an iterative and standing part of the process of learning which is intended to setting the hypotheses and testing the formal and mental models. He described it with the following steps: Determination of a problem, Setting a dynamic hypothesis, Setting a simulation model, Testing, and Design of the strategy.

\section{Results}

\section{Casual loop model}

The development of complementary activities on the farm, especially if these are such where bigger financial investment (e.g. the development of tourism) is necessary not only on the level of farming establishment but also on the level of national and international policies, represents a dynamic and complex system which demands a developed ability of system thinking and the use of methods of system dynamics in order to determine and control the important issues.

Figure 2 represents the causal loop diagram of system structure - diversification of farming establishments in tourist farms with important consequences for the region and the farming establishment (Žibert et al., 2019). 
Figure 2

Causal loop diagram of system structure - diversification of farming establishments in tourist farms

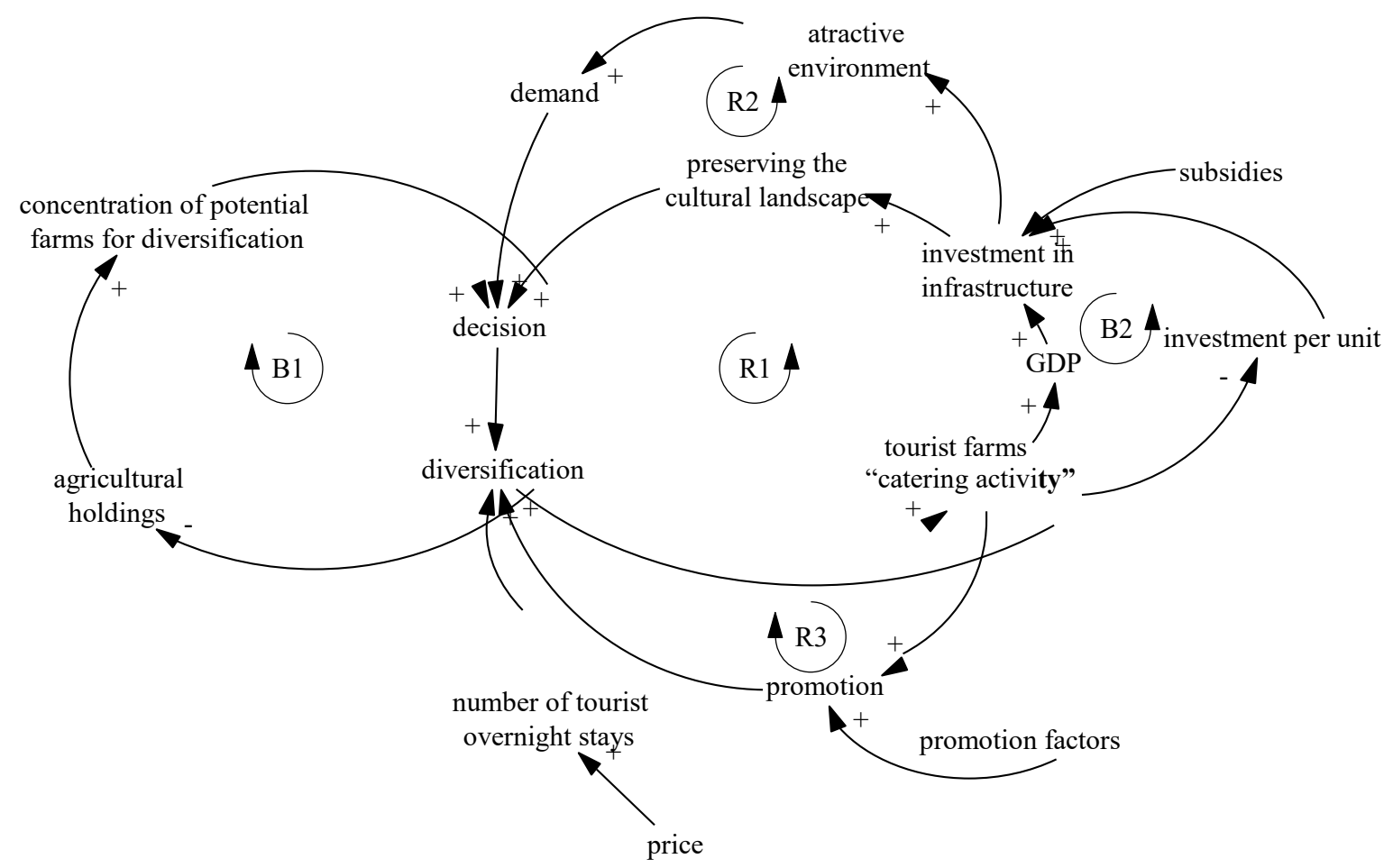

Source: Author's illustration

According to an analysis of the environment (the study of practice) and following the previous research in this field (Sharpley, 2002) the simulation model should consider the key variables we have identified:

- The number of tourist overnight stays in the area,

- The number of agricultural holdings,

- The transition of the holding into a tourist farm,

- Subsidies,

- General organization and affection for tourism,

- The promotion of tourism,

- Environmental acceptability of rural tourism development

A key variable in the model is the number of tourist farms. This is a form with supplementary activity (which is catering activity) on the farm. From 2018 to 2019, the number of tourist farms in Slovenia increased from 1075 to 1126 , although the number of farms has decreased. During the development of casual loop diagram, the key variables were identified:

- The number of potential farms (agricultural holdings) for diversification to farm tourism

- The number of tourist farms with

- The flow between them

In the system dynamics model (Figure 2), we can see several main feedback loops which represent reinforcing (R1, R2 and R3) and balance (B1 and B2). The loops R1, $\mathrm{R} 2$, and R3 indicate the developmental activity. 
In reinforcing loop R1 increasing or growth of GDP influences investments in infrastructure directly, which has positive consequences on the environment mostly, as this is the way it is preserved more easily. Besides, the destinations are more easily accessible. At the same time, it influences environmental attractiveness. This attractiveness of the environment increases the demand for lodging and/or visiting destinations (reinforcing loop R2). Increasing the demand influences positively the decision of farming establishment whether it will diversify its primary industry. As already mentioned, this diversification influences economic effects, employability, and the quality of life positively. By the development of supplementary activity - farm tourism, the opportunities emerge for the development of other supplementary activities related to the cultivation of primarily agricultural crops, the sales of agricultural crops and products of farms, activities which are connected to traditional knowledge on farms, and social security services. Not all the farms' establishments are suitable for the diversifying of tourism activities. However, as they expand their activities, there remains a smaller number of agricultural holdings that would exclusively deal with agriculture (B1).

An important variable of system structure is also the promotion factor (reinforcing loop R3). Not in the sense of promotion of the industry that tourism is the catalyst which would help in economic challenges of the countryside (Hoggart et al., 1995; Williams \& Shaw, 1998), but in the sense of the promotion of tourist farms, destinations, the tradition of cultural habits, events, and environment whose part is the farming establishment itself. These are, therefore, the tools which are available to farms or broader groups of entities, and through which they communicate with their target publics about all the matters which influence the profitability and, primarily, the decision for the step of diversification (Podnar \& Golob, 2001).

Despite everything, however, the share of GDP cannot entirely cover the investments in infrastructure which helps in the development of the tourist industry. Gartner (2004) reports on numerous support rates in the development of the industry. Despite that, however, the share of investments in infrastructure per unit shows one of the decisive equalization loops (B2). An important factor that decides whether a farm will diversify its primary activity and spread to the field of tourism is the revenue the farm receives. The latter is divided into several types. We speak about the profit the farm creates with its primary activity and about subventions that the farm can receive with the purpose to spread its activity. Subventions are a financial aid which farms receive from different sources (local, national or international). They can be onetime or long-lasting. Farms do not have to repay them. In the programing period 2014-2020 (RDP, 2014), the Rural Development Programme (it is a programing document of an individual member state of the EU which is the basis for the absorption of the financial funds from the European Agricultural Fund for Rural Development) anticipates some changes in a way that app. The amount of 10 million Euros of subventions would be allocated to farms in the Republic of Slovenia for the development of tourism in the countryside.

The next step in the system dynamics modelling process shows the system dynamics model for farm tourism development (as supplemented activities which are catering activities). It was based on the casual loop model presented in Figure 2.

\section{Model development}

A system dynamics model structure is shown in Figure 3. The methodology of system dynamics was defined by Forrester (1997) and Sterman (2000). The models of the system dynamics are composed of level elements that represent flows, stock, and levels of the system and auxiliary elements. 
Figure 3

System dynamics model of tourist farms

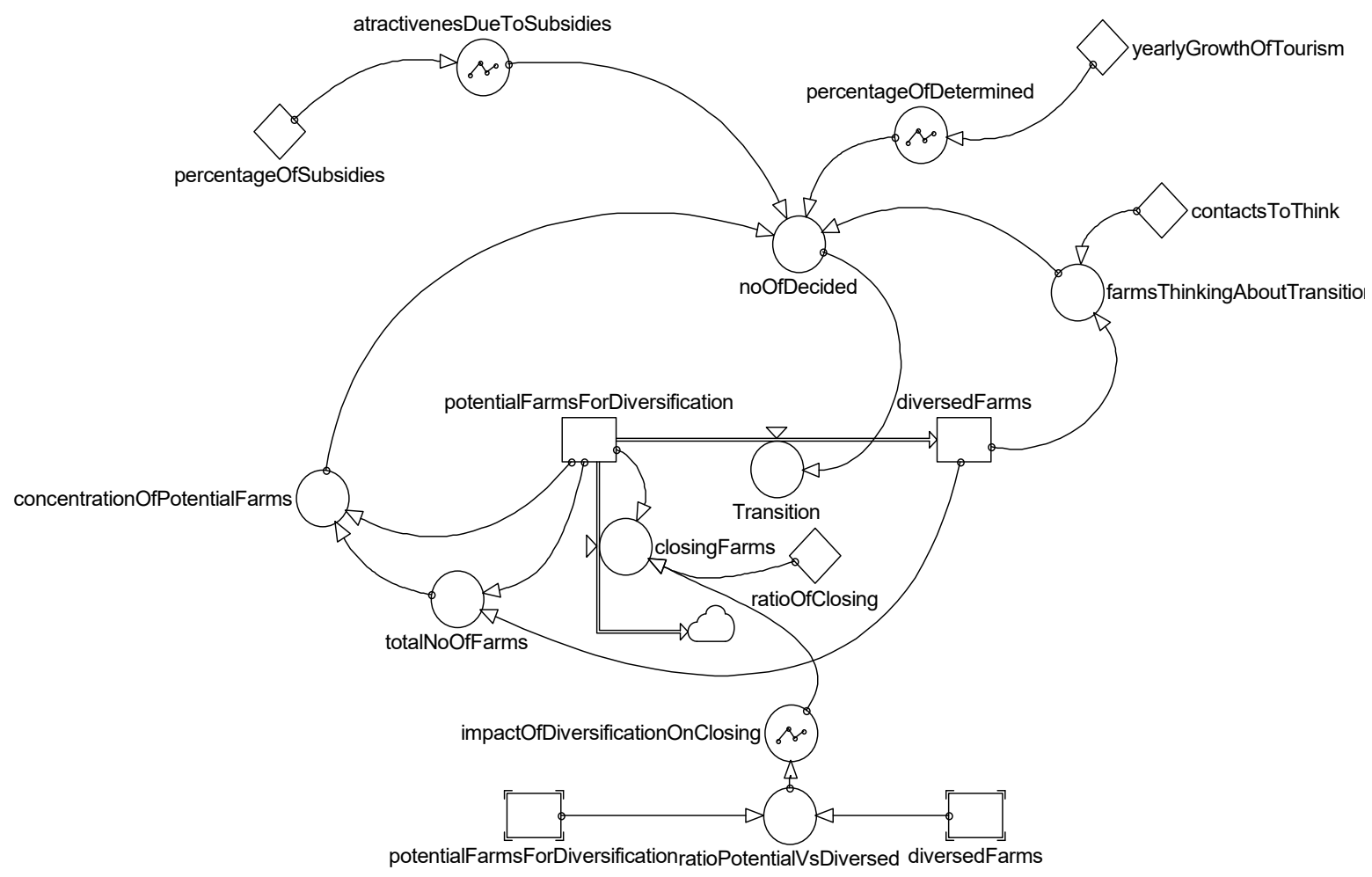

Source: Author's illustration

There are two levels present in the developed to the elements of the model. The variable "potentialFarmsForDiversification" represents the number of farms that are suitable for the transition. Farms in Slovenia with supplementary activity - tourism (which is catering activity) use 11.60 ha of utilized agricultural area (CAFS, 2017). We have identified the potential farm with acreage between 10 and 15 ha of utilized agricultural area. By the flow "Transition" the "potentialFarmsForDiversification" become "diversedFarms". In 2018 there were 1,075 tourist farms (which was a catering activity) in Slovenia. One of the most important problems is the decreasing number of farms in Slovenia. On average, each year in the last period $1 \%$ of farms is lost (SORS, 2020). "PotentialFarmsForDiversification" has been influenced by the element "closingFarms", which has been gotten by multiplying "ratioOfClosing" with the function"impactOfDiversificationOnClosing"

and "potentialFarmsForDiversification". Average yearly closing of farms in Slovenia from 2003 to 2016 is $2 \%$. That presents an element "ratioOfClosing". In the model, we have set it as a constant 0.02 .

If the proportion diversification is larger, we expect, that the income will improve and fewer farms will close their business. When the ratio is present as potential: diver $=5: 1,2 \%$ of potential farms leave the business. If income would be higher none would leave. That is what we present with the function "impactOfDiversificationOnClosingu. An element "RatioPotentialVsDiversed" represent input to the graph function "impactOfDiversificationOnClosingu. We get this ration by subtracting the number of farms that have diversified from farms that are suitable for the transition.

The flow "transition" in the model is associated with "noOfDecided", which represents the number of farms that decide to make a transition. That number has been gotten by multiplying "concentrationOfPotentialFarms" with 
"farmsThinkingAboutTransition",

"percentageOfDetermined"

and "atractivenesDueToSubsidies". The" concentrationOfPotentialfarms" is obtained by dividing the number of "potentialFarmsForDiversification "by the "totalNoOfFarms", where "totalNoOfFarms "present the sum of potential farms for diversification and diverse farms. The variable "FarmsThinkingAboutTransition" represents several farms, that think about transition due to information spread. This variable has been getting by multiplying "contactsToThink" and "diversedFarms". The element "contactsToThinku represents a constant. It has been set as a constant of 5. One new diverse farm triggers 2 other farms to consider the transition. Yearly, 1\% out of 5415 potential farms for diversification turns to diversified. That would mean 54 farms.

"YearlyGrowthOTtourism" is input to the graph function "percentage OfDetermined».

Effect of subsidies on the transitions represents the function "atractivenesDueToSubsidies" where an element "percentageOfSubsidies" represents its input. The proportion of diversification investment coverage represents a constant - "percentageOfSubsidies", where its value in the model is 0.85 .

Equations and parameters, as well as user defined functions, are quantified; the model is mathematically formulated (appendix).

\section{Model calibration and validation}

Validation of the model is an important part of the methodology (Forrester, 1994; Pejić-Bach\& Čerić, 2007; Rahmandad \& Sterman, 2012; Sterman, 2000). To perform the validation the model was upgraded with the Mean Squared Error auxiliary variable and Cumulative Mean Squared Error level element which is shown in Figure 4.

Figure 4

A model with added Mean Squared Error auxiliary element and Cumulative Mean Squared Error level element

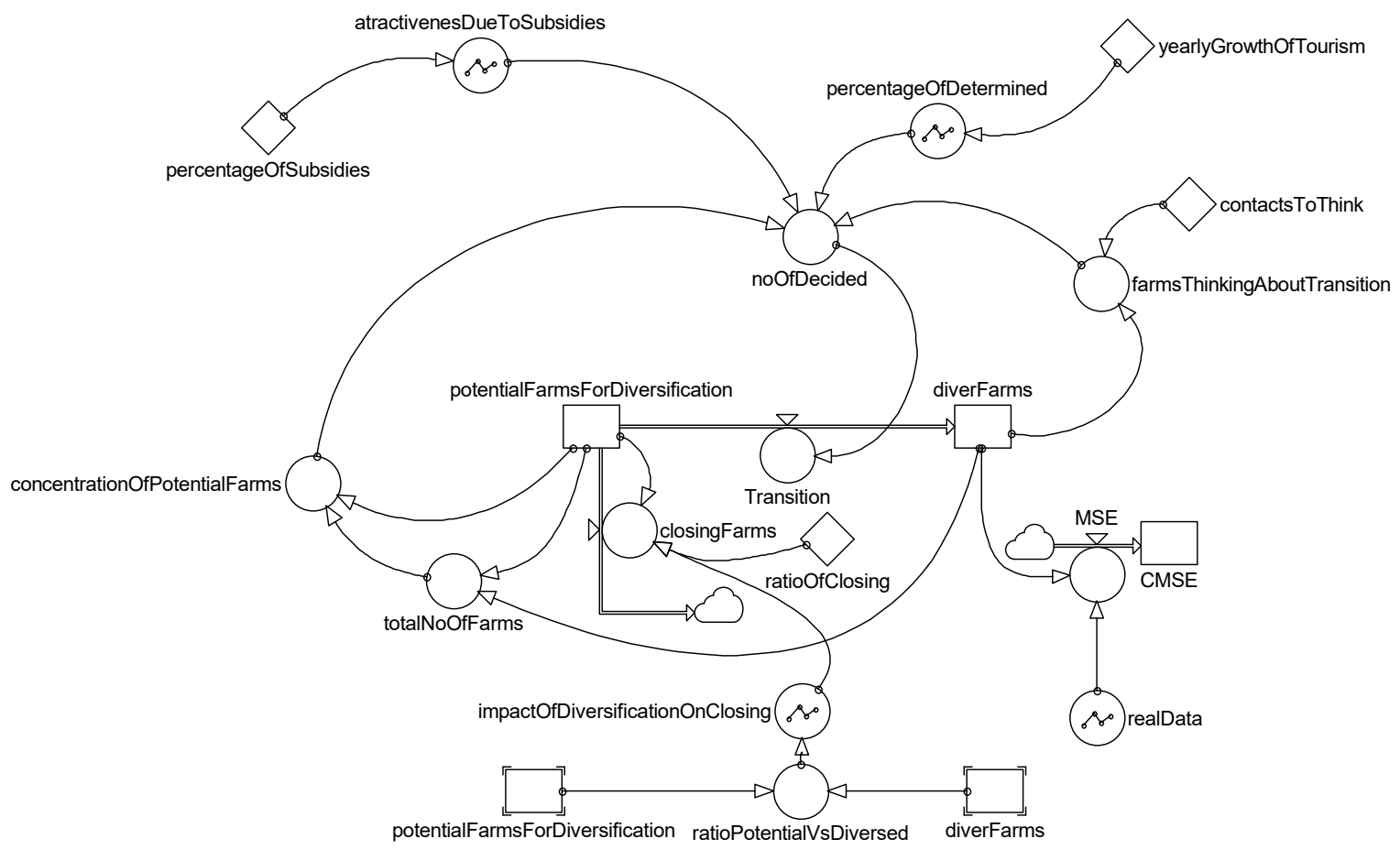

Source: Author's illustration 
Here we compared the estimated number of Farms with diversification from statistical data and simulation results in the period of ten years from 2008 to 2017. In the next step of the validation, we have used Powersim Solver with Genetic Algorithms, where we have varied the following parameters which are gathered in presented in Table 1. Here the initial value, as well as lower boundary and upper boundary, is shown. The target minimum value of the optimization was Cumulative of Mean Squared Error, i.e. we wanted that the difference between simulation and real data would be as small as possible.

\section{Table 1}

Parameters for optimization with Genetic Algorithms

\begin{tabular}{llll} 
Parameter & Init. value & Lower Boundary & Upper Boundary \\
percentageOfSubsidies & 0.5 & 0.2 & 0.95 \\
yearlyGrowthOfTourism & 0.0 & 0 & 0.15 \\
contactsToThink & 5 & 1 & 10 \\
\hline ratioOfClosing & 0.01 & 0.001 & 0.02
\end{tabular}

Source: Author's work

After the performed optimization with Genetic Algorithms, where we have used 100 generations with the same size of population the best parameters had the following values: percentageOfSubsidies $=0.89$, yearlyGrowthOfTourism $=0.085$, contactsToThink $=4.5$, ratioOfClosing $=0.019$. Figure 5 shows a comparison of real data (1) and simulated (2) response to the best parameter set found by Genetic Algorithms optimization.

Figure 5

Comparison of real data (1) and simulated (2) response fort he best parameter set found by Genetic Algorithms optimization

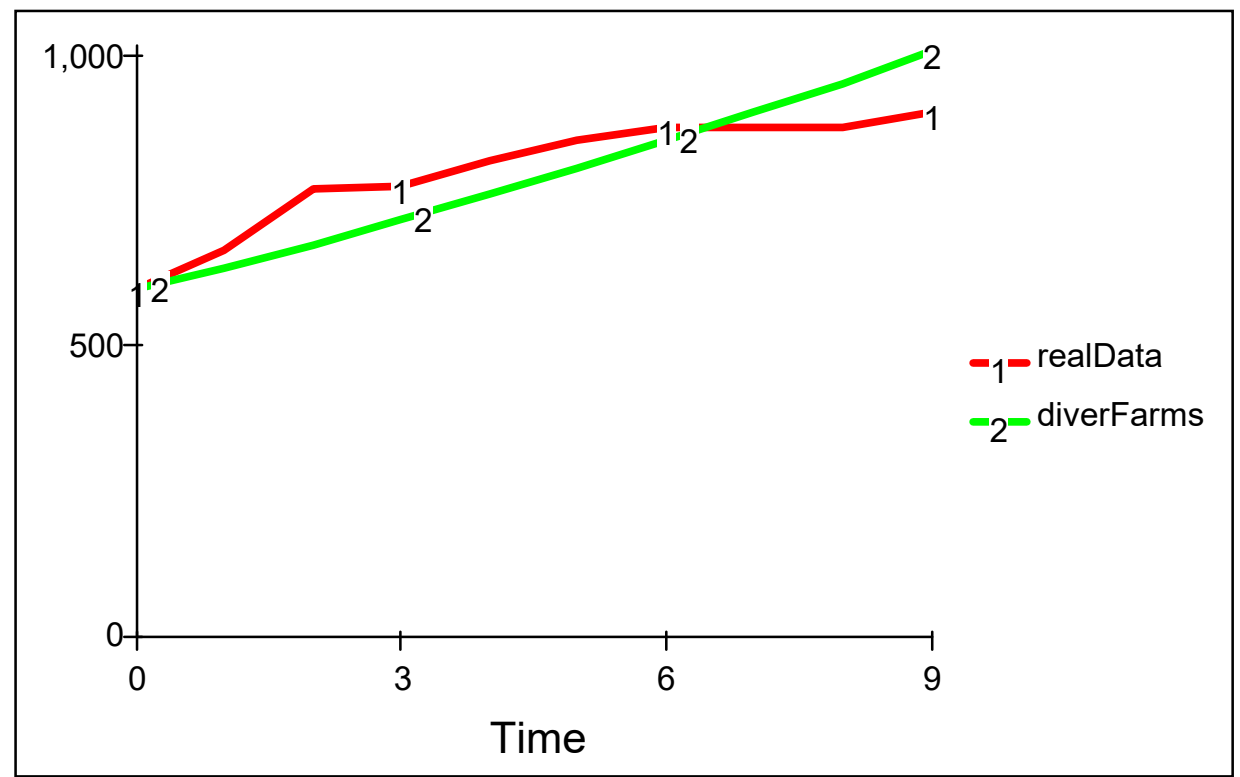

Source: Author's illustration

In order to perform formal validation (Oliva, 2003; Pejić-Bach\& Čerić, 2007) the Theil validation statistics (Oliva, 1995) was performed which results are reported in Table 2 One has to take into consideration that we have available only 10 points for validation. Therefore the $\mathrm{R}^{2}$ value of 0.82 shows relatively good correlation. More 
informative is Mean Abs. Percent Error which is only 6\%; this is the average deviation from the real data.

Table 2

Theil validation statistics (Oliva, 1995) for the number of farms, that diversified $\mathrm{N}=10 \quad$ Parameter: Number of Farms

$\mathbf{R}^{2}$ 0.82

Mean Abs. Percent Error 3736.9

Mean Square Error $\quad 61.13$

Root Mean Square Error 0.01

Bias $\quad 0.03$

Variation 0.34

Covariation $\quad 0.63$

Source: Author's work

In order to perform more thorough validation, the additional data should be gathered, however, the data is scarce in the field of Farm diversification. The appropriate data should be gathered by the Statistical Bureau of the Republic of Slovenia in order to perform additional validation tests of the model. Nevertheless, the computed Theil statistics provides promising results for future model development and shows the methodological approach to quantitative validation.

Scenario analysis

Table 3 shows parameter values for eight simulation scenarios SC1-SC8. The parameters that are varied are: percentageOfSubsidies, yearlyGrowthOfTourism, contactsToThink and ratioOfClosing. Change in parameters are shown with underline and grey table cell. Base values of the parameters were: percentageOfSubsidies = $50 \%$, yearlyGrowthOfTourism $=8 \%$, contactsToThink $=5$ and ratioOfClosing $=1 \%$.

Table 3

Scenarios with parameter values

\begin{tabular}{lllll} 
Scenario & $\begin{array}{l}\text { Percentage } \\
\text { OfSubsidies }\end{array}$ & $\begin{array}{l}\text { Yearly } \\
\text { GrowthOfTourism }\end{array}$ & $\begin{array}{l}\text { Contacts } \\
\text { ToThink }\end{array}$ & $\begin{array}{l}\text { Ratio } \\
\text { OfClosing } \\
\text { SC1 }\end{array}$ \\
\hline 5 & 0.08 & 5 & 0.01 \\
SC2 & 95 & 0.08 & 5 & 0.01 \\
SC3 & 50 & 0.04 & 5 & 0.01 \\
SC4 & 50 & 0.15 & 5 & 0.01 \\
SC5 & 50 & 0.08 & 1 & 0.01 \\
SC6 & 50 & 0.08 & 10 & 0.01 \\
SC7 & 50 & 0.08 & 5 & 0.005 \\
SC8 & 50 & 0.08 & 5 & 0.02
\end{tabular}

Source: Author's work

Results of eight scenarios are shown in Figure 6. On the left side, the number of Farms with diversification is shown, in the middle the intensity of Farm closing is shown and on the right side the transition from potential Farms to Farms with diversification is shown. On the x-axis, the time is shown with the unit 1 [year]. One can observe, that SC1, SC3 and SC5 result in low transition rates, SC7 and SC8 provides moderate growth and SC2, SC6 and SC4 provide fast growth of the number of Farms with Diversification. 
Figure 6

Results of eight simulation runs

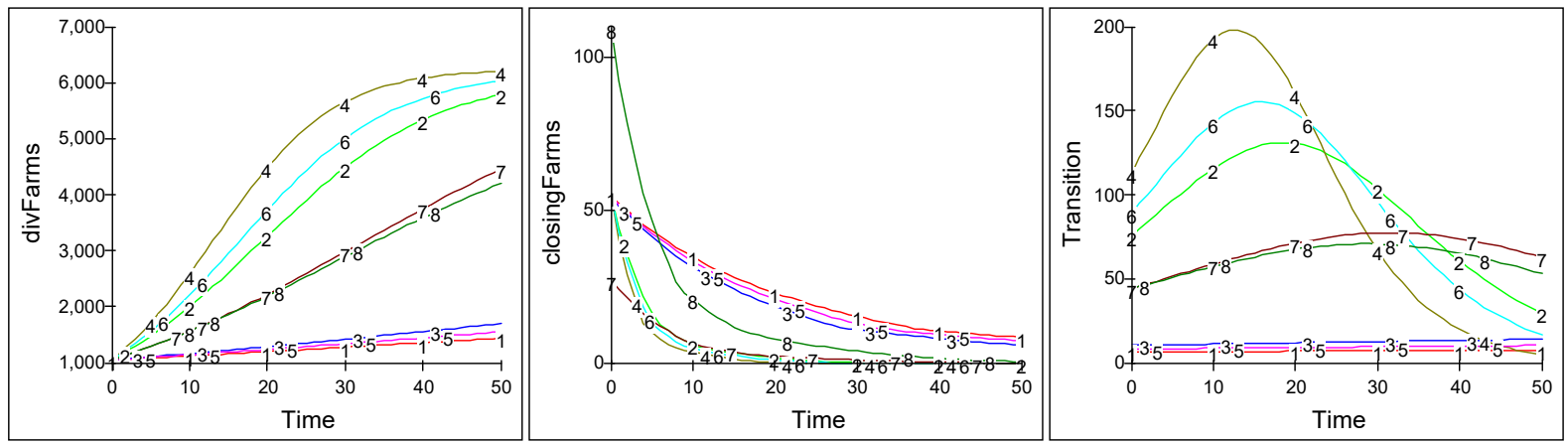

Source: Author's illustration

By the provided results, one can identify the main driving forces of the system, which are: a) subsidies, b) Tourism branch growth and c) Promotion of diversification. It is also interesting, that larger intensity of closing of the farms would also lead to lover transition rates which are not desirable.

\section{Discussion}

There are many equal depictions for the computer simulation of systems. A display of the casual loop model is the foundation for qualitative modelling. In our article, we explained the course and the dynamics of the process of diversification on nonagricultural activities on the farm.

It is almost sure that the parameters, that we used in different scenarios will not remain constant for that long period. One of the important findings is that the system is sensitive to changes in subsidies, promotion of diversification and with the growth of Tourism branch. Promotion of diversification means the policy for promoting the development of supplementary activities at farms (related to tourism). Also according to Gunn (1988), tourism development (also farm tourism) involves several components to be successful: attractions, tourism infrastructure, services, hospitality and promotion. The importance of promotion is also perceived in the casual loop model as a positive feedback loop. The "ratioOfClosing" represent the average yearly closing of farms in Slovenia. This value is initially set to 0.01. As we explained by model development description, the yearly average closing of farms in Slovenia from 2003 to 2016 is $2 \%$. The "yearlyGrowthOfTourism" present the yearly average growth of tourism. In Slovenia from 2010 to 2018 is $8 \%$. We have set it as a constant 0.8. In the case, that the yearly growth of tourism branch is $8 \%$, the growth in new diversified farms is approximately $1 \%$. This can be also used, with come correction, as the part, which determines how many of those who think about the transition will perform the transition. SC4 shows the impact of grater yearly growth of tourism. According to SC4, the largest transition would be achieved in 15 years.

Comparing scenarios SC1, SC2 and SC3, which shows a distinct subsidy rate, more intensive transition is observed. The more subsidies, the greater and faster is the transit from potential to diverse farms. In scenario SC3, the impact of decreasing the "yearlyGrowthOfTourism" is considered. Scenario SC3 is familiar to scenario SC5, but with the differences in two elements - in "yearlyGrowthOfTourism" and in "contactsToThink". In both cases, one of the factors (contact to think or yearly growth of tourism) is really low. One more time it shows a testament to how important these two factors are for our transit. Scenarios SC7 and SC8 provides moderate 
growth. Due to the lower "ratioOfClosing" scenario, SC7 achieves higher farm transition, which is understandable.

Our research has certain limitations. The data is scarce in the field of Farm diversification in Slovenia, especially in the field of tourism. The appropriate data should be gathered by the Statistical Bureau of the Republic of Slovenia, but in 2015, the policy of introducing supplementary activities changed and many of the data of recent years are irrelevant or difficult to compare. And behind that, this system dynamics model is partially related to the casual loop model and covers only the main feedback loops $B 1$ and $\mathrm{R} 1$. This model does not provide numerical forecasts. It is rather a policy tool that examines the behaviour of key variables over time. Furthermore, models explain why specific outcomes are achieved.

Today, tourism and complementary activities enable a large percentage of GDP. A sensible question emerges where there is a boundary until this growth can endure and, consequentially, how many tourists can accept a certain area. Namely, these answers are necessary so that we can further think about the element of subvention and about the amounts by which the farms would finance by themselves with the purpose of the development of additional non-agricultural contents in farming establishments.

\section{Conclusion}

In this paper, we presented a qualitative causal loop modelnd a system dynamics model used for the simulation of transition of farming establishments in tourist farms for the purpose of increasing profitability trough the diversification. The system dynamics model enables the simulation of the behaviour of the real system when testing the effects of alternative decisions in time.

After performing several simulation scenarios, we discovered that transition to diverse farms relies on subsidies that provide the main motivation for the transition. However, the subsidies are not the only driving force in the system; there are also two other elements: rate of tourism growth and promotion of diversification. One of the important advantages represented by the system dynamics model is the ability of the response of the target variables in certain periods. It is a useful tool for decisionmakers in connection with the further development of tourism in the countryside. Comparison with previous research (Goeldner \& Ritchie, 2007; Ritchie \& Zins, 1978) indentified the main variables which considered the development of tourism activities in the rural area. But, in addition to recognizing them, we have also shown the impact they have on each other when developing tourism through agricultural diversification.

In summary, our work indicate that the dynamic response of the system should be taken into account in further strategic decisions regarding the development of tourism famrs. In particular, the role of subsidies, tourism branch growth and promotion of diversification must be taken into account. We can conclude that the system dynamics model can be regarded as a useful decision support tool for policymaking. Scenario results indicated that an important factor that influences the downward trend in the number of agricultural holdings is farm income, which can be improved by diversification. However, the model has its limitations, that mainly stsem from the fact that this system dynamics model is only partially related to the causal loop model and covers only the main feedback loops. Therefore, to further development of a model, that will predict even the broad range of various scenarios, more versatile model should be developed, incorporating sectors, such as sustainability and impact to the demography. 


\section{References}

1. Arroyo, C. G., Barbieri, C., Rich, S. R. (2013), "Defining agritourism: A comparative study of stakeholders' perceptions in Missouri and North Carolina", Tourism Management, Vol. 37, pp. 39-47.

2. Barbieri, C. (2010), "An importance-performance analysis of the motivations behind agritourism and other farm enterprise developments in Canada", Journal of Rural and Community Development, Vol. 5, No. 1.

3. Bastan, M., Ramazani Khorshid-Doust, R., Delshad Sisi, S., Ahmadvand, A. (2018), "Sustainable development of agriculture: a system dynamics model", Kybernetes, Vol. 47, No. 1, pp. $142-162$.

4. Bel, F., Lacroix, A., Lyser, S., Rambonilaza, T., Turpin, N. (2015), "Domestic demand for tourism in rural areas: Insights from summer stays in three French regions", Tourism Management, Vol. 46, pp. 562-570.

5. Blumberga, A., Bazbauers, G., Davidsen, P. I., Blumberga, D., Gravelsins, A., Prodanuks, T. (2018), "System dynamics model of a biotechonomy", Journal of Cleaner Production, Vol. 172, pp. $4018-4032$.

6. Bontkes, T. S., van Keulen, H. (2003), "Modelling the dynamics of agricultural development at farm and regional level", Agricultural Systems, Vol. 76, No. 1, pp. 379-396.

7. Brailsford, S., Churilov, L., Dangerfield, B. (2014), Discrete-event Simulation and System Dynamics for Management Decision Making. Wiley, Chichester.

8. Busby, G., Rendle, S. (2000), "The transition from tourism on farms to farm tourism", Tourism Management, Vol. 21, No. 6, pp. 635-642.

9. CAFS. (2017), Chamber of Agriculture and Forestry of Slovenia, available at https://www.kgzs.si/uploads/dokumenti/strokovna_gradiva/analiza_dopolnilnih_dejavnost i.pdf/(17 April 2020)

10. Cunha, C., Kastenholz, E., Carneiro, M. J. (2018), "Lifestyle entrepreneurs: the case of rural tourism", in Carvalho L., Rego C., Lucas M., Sánchez-Hernández M., Noronha A. (Eds.), Entrepreneurship and Structural Change in Dynamic Territories, Springer, Cham, pp. 175188.

11. Dernoi, L. (1983), "Farm tourism in Europe", Tourism Management, Vol. 4, No. 3, pp. 155166.

12. Forrester J. W. (1994), "System dynamics, systems thinking, and soft OR", System Dynamics Review, Vol. 10, pp. 245-256.

13. Forrester, J. W. (1997), "Industrial dynamics", Journal of the Operational Research Society, Vol. 48, No. 10, pp. 1037-1041.

14. Gartner, W. (2004), "Rural tourism in the USA", International Journal of Tourism Research, Vol. 6, No. 3, pp. 151-164.

15. Giaccio, V., Mastronardi, L., Marino, D., Giannelli, A., Scardera, A. (2018), "Do rural policies impact on tourism development in Italy? A case study of agritourism", Sustainability, Vol. 10, No. 8, 2938.

16. Goeldner, C. R., Ritchie, J. B. (2007). Tourism Principles, Practices, Philosophies, John Wiley \& Sons, New Jersey.

17. Groot, J. C., Rossing, W. A., Tichit, M., Turpin, N., Jellema, A., Baudry, J., Verbung, P. H., Doyen, L., Van de Ven, G. W. (2009), "On the contribution of modelling to multifunctional agriculture: learning from comparisons", Journal of Environmental Management, Vol. 90, No. 2, pp. 147-160.

18. Gunn, C. A. (1988). Tourism Planning (2 nd ed.), Taylor \& Francis, New York.

19. Hoggart, K., Buller, H., Black, R. (1995). Rural Europe: Identity and Change, Arnold, London.

20. Jaafar, M., Bakri, N. M., Rasoolimanesh, S. M. (2015), "Local community and tourism development: a study of rural mountainous destinations", Modern Applied Science, Vol. 9, No. 8, pp. 399.

21. Jakulin, T. J. (2016), "System dynamics models as decision-making tools in agritourism", Agricultura, Vol. 13, No. 1-2, pp. 5-10.

22. Johnson, T. G., Bryden, J. M., Refsgaard, K. Lizarraga, A. S. (2008), "A system dynamics model of agriculture and rural development: the topmard core model", 107th Seminar of 
European Association of Agricultural Economists, 30 January-1 February, EAAE, Sevilla, Spain.

23. Kheiri, J., Nasihatkon, B. (2016), "The effects of rural tourism on sustainable livelihoods (case study: Lavij rural, Iran)", Modern Applied Science, Vol. 10, No. 10, pp. 10-22.

24. Lazanski, T. J., Kljajić, M. (2006), "Systems approach to complex systems modelling with special regards to tourism", Kybernetes: the International Journal of Systems \& Cybernetics, Vol. 35, No. 7-8, pp. 1048-1058.

25. Muresan, I., Oroian, C., Harun, R., Arion, F., Porutiu, A., Chiciudean, G., Todea, G., Lile, R. (2016), "Local residents' attitude toward sustainable rural tourism development", Sustainability, Vol. 8, No. 1, 100.

26. Ollenburg, C., Buckley, R. (2007), "Stated economic and social motivations of farm tourism operators", Journal of Travel Research, Vol. 45, No. 4, pp. 444-452.

27. Oliva, R. (1995), "A Vensim module to calculate summary statistics for historical fit", D4584, System Dynamics Group, Massachusetts Institute of Technology, Cambridge, MA.

28. Oliva, R. (2003), "Model calibration as a testing strategy for system dynamics models", European Journal of Operational Research, Vol. 151, No. 3, pp. 552-568.

29. Oppermann, M. (1996), "Rural tourism in southern Germany", Annals of Tourism Research, Vol. 23, No. 1, pp. 86-102.

30. Pejić-Bach, M., Čerić, V. (2007), "Developing system dynamics models with" step-by-step" approach", Journal of Information and Organizational Sciences, Vol. 31, No. 1, pp. 171185.

31. Park, D. B., Nunkoo, R., Yoon, Y. S. (2015), "Rural residents' attitudes to tourism and the moderating effects of social capital", Tourism Geographies, Vol. 17, No. 1, pp. 112-133.

32. Podnar, K., Golob, U. (2001) "The problem of advertorial and commercialization of Slovene press", in Podnar, K., Pušnik, M., Senić, N. (Eds.), Graduate Conference on Media and Culture, 10-12 May, Faculty of Social Sciences, Pristop, Ljubljana, pp. 53- 63.

33. Rahmandad, H., Sterman, J. D. (2012), "Reporting guidelines for simulation based research in social sciences", System Dynamics Review, Vol. 28, No. 4, pp. 396-411.

34. Richmond, B. (1993), "System thinking: critical thinking skills for the 1990s and beyond", System Dynamics Review, Vol. 9, No. 2, pp. 113-133.

35. Ritchie, J. B., Zins, M. (1978), "Culture as determinant of the attractiveness of a tourism region", Annals of Tourism Research, Vol. 5, No. 2, pp. 252-267.

36. Rozman, Č., Pakež, K., Kljajić, M., Bavec, M., Turk, J., Bavec, F., Kofjač, D., Škraba, A. (2013), "The dynamic simulation of organic farming development scenarios - a case study in Slovenia", Computer and Electronics in Agriculture, Vol. 96, pp. 163-172.

37. Rozman, Č., Kljajić, M., \& Škraba, A. (2015), "System dynamics model for conversion to organic farming", Журна^ Сибирского фелерального университета. Серия «Математика и фризика», Vol. 8, No. 1, pp. 64-74.

38. RDP. (2014), Rural Development Programme, available at: https://www.programpodezelja.si/images/SPLETNA_STRAN_PRP_NOVA/1_PRP_2014-

2020/1_1_Kaj_je_program_razvoja_pode\%C5\%BEelja/7._sprememba_PRP/Programme_201 4SI06RDNP001_9_1_sl.pdf (16 April 2020)

39. Sedarati, P. (2015), "System dynamics in tourism: a systematic literature review", Doctoral dissertation. University of Algarve, Faculty of Economics.

40. Sharpley, R. (2002), "Rural tourism and the challenge of tourism diversification: the case of Cyprus", Tourism management, Vol. 23, No. 3, pp. 233-244.

41. Sharpley, R., Vass, A. (2006), "Tourism, farming and diversification: an attitudinal study", Tourism management, Vol. 27, No. 5, pp. 1040-1052.

42. SORS. (2017), "In 2017 the real factor income per employee in agriculture expected to decrease by $15 \%$ over 2016", available at https://www.stat.si/statweb/News/Index/7109 / (7 June 2019)

43. SORS. (2020), "Agricultural holdings, general overview, Slovenia, by years", available at: https://pxweb.stat.si/SiStatDb/pxweb/sl/30_Okolje/30_Okolje_15_kmetijstvo_ribistvo_03_k metijska_gospod_00_15560_splosno/1556001S.px/chart/chartViewLine/ (15 April 2020)

44. Sterman, D. J. (2000), Business Dynamics: System Thinking and Modeling for a Complex World, Irwin McGraw-Hill, Boston. 
45. Su, M. M., Wall, G., Wang, Y., Jin, M. (2019), "Livelihood sustainability in a rural tourism destination-Hetu Town, Anhui Province, China", Tourism Management, Vol. 71, pp. 272281.

46. Tew, C., Barbieri, C. (2012), "The perceived benefits of agritourism: The provider's perspective", Tourism Management, Vol. 33, No. 1, pp. 215-224.

47. Williams, A., Shaw, G. (1998). Tourism and economic development: European experiences (3rd ed.), Wiley, Chichester.

48. Xue, L., Kerstetter, D., Hunt, C. (2017), "Tourism development and changing rural identity in China", Annals of Tourism Research, Vol. 66, pp. 170-182.

49. Žibert, M., Rozman, Č., Prevolšek, B., Škraba, A. (2019). "The system dynamics model for diversification of agricultural holdings into farm tourism", in Zadnik Stirn, L. (Ed.), et al., SOR '19 proceedings. Ljubljana: Slovenian Society Informatika, Section for Operational Research. 2019, pp. 34-38.

50. Žibert, M., Rozman, Č., Prevolšek, B., Škraba, A. (2020). "Attributes of the agricultural holding for diversification of farm activities", in Celec, R. (Ed.), Ecological Influences on Different Life Aspects, Dr. Kovač, Hamburg, pp. 105-122.

\section{About the authors}

Maja Žibert achieved her master study at the University of Maribor, Faculty of Tourism. Currently, she is a PhD student in agrarian economics (Faculty of Agriculture and Life Sciences, University of Maribor). She is active as a teaching assistant at the Faculty of the Tourism University of Maribor. Her research includes papers in destination management, wine tourism, rural tourism area and system dynamics. In year 2014/2015 she was regional Wine Queen of Slovenia and in 2017 she was Slovenian Wine Queen. The author can be contacted at maja.zibert@student.um.si

Črtomir Rozman received his PhD at the University of Maribor, Faculty of Agriculture. $\mathrm{He}$ is active as a full professor of farm management in the Department for Agriculture Economics and Rural Development. His research includes the development of decision-support systems for farm management (simulation modelling, multi-criteria decision analysis, machine learning) and the economics of agricultural production. $\mathrm{He}$ is the author or co-author 86 scientific papers, 43 with journal citation report impact factor. He is also an author or co-author of 7 scientific books and 25 book chapters. The author can be contacted at crt.rozman@um.si

Andrej Škraba obtained his BSc, MSc and PhD in the field of Organizational Sciences - Informatics from the University of Maribor in 1995, 1998, and 2000, respectively. He works as a professor and researcher in the Cybernetics \& Decision Support Systems Laboratory at the University of Maribor, Faculty of Organizational Sciences. His research interests cover systems theory, modelling and simulation, cyber-physical systems, the internet of things and decision processes. Prof. Škraba has received a Bronze Medal of University of Maribor, for successful research and pedagogical work in the field of Systems Modeling and Simulation in 2003. He is a member of the System Dynamics Society (SDS) and the Slovenian Society for Simulation and Modelling (SLOSIM). The author can be contacted at andrej.skraba@um.si

Boris Prevolšek is a teaching assistant and lecturer at the Faculty of Tourism, the University of Maribor in Brežice. He received his Master of Science in 2012 from the Faculty of Economics and is currently enrolled in his PhD Studies at the Faculty of Agriculture and Life Sciences of the University of Maribor. As a researcher, he is interested in various topics concerning tourism, also safety in tourism and rural development. He co-authored 6 scientific papers, 2 scientific books and 4 book chapters. The author can be contacted at boris.prevolsek@um.si 


\section{Appendix 1. Model Equations}

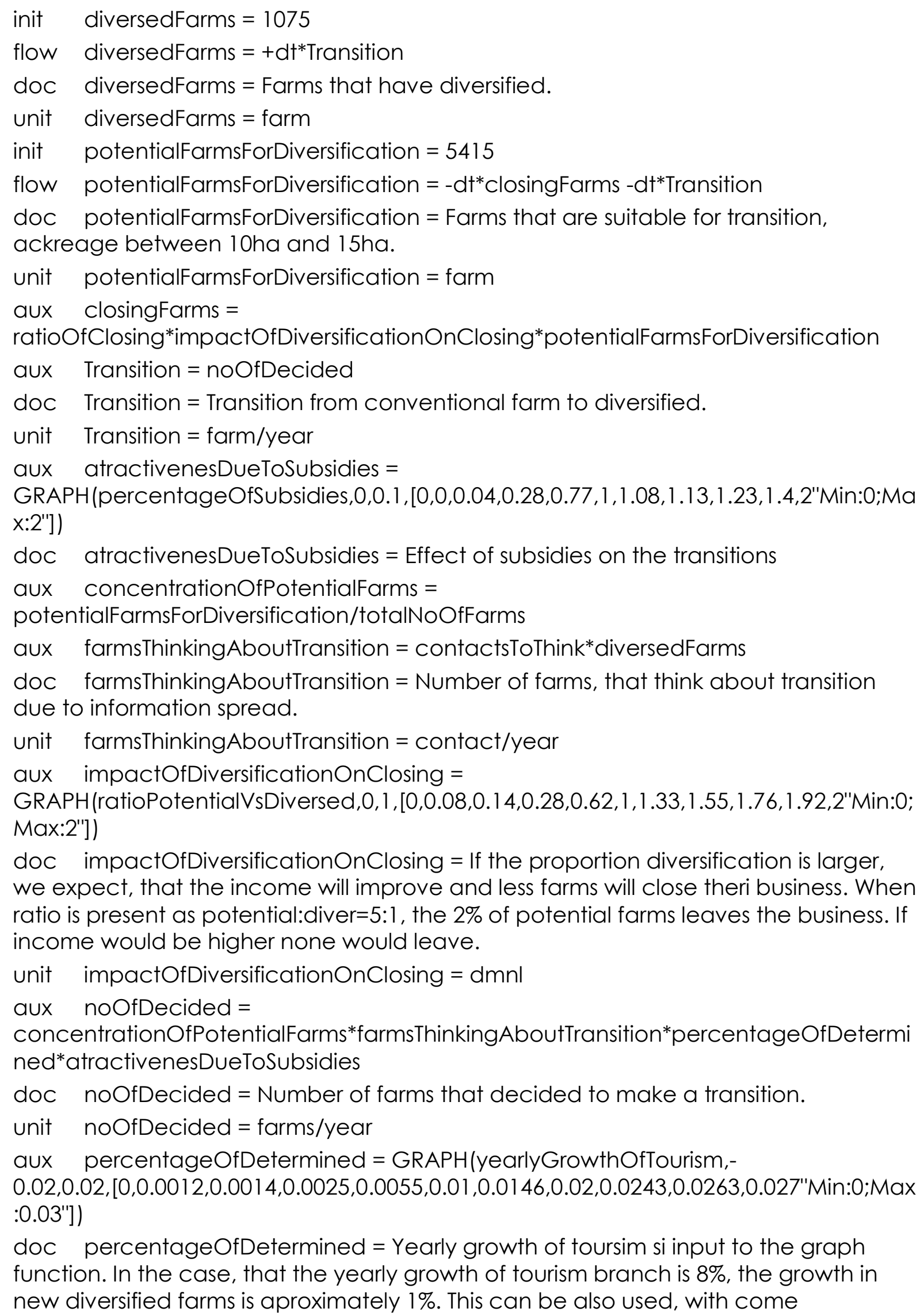


correction, as the part, which determines how many of those who thing about transition will actually perform the transition.

unit percentageOfDetermined $=$ dmnl

aux ratioPotentialVsDiversed $=$ potentialFarmsForDiversification/diversedFarms

aux totalNoOfFarms = potentialFarmsForDiversification+diversedFarms

doc totalNoOfFarms = Sum of potential farms for diversificatin and diversed farms .

unit totalNoOfFarms $=$ farm

const contactsToThink $=5$

doc contactsToThink = One new diversed farm triggers 2 other farms to consider transition. Yearly, $1 \%$ out of 5415 potential farms for diversification turns to diversified. That would mean 54 farms.

unit contactsToThink $=$ contacts $/$ farm $/$ year

const percentageOfSubsidies $=0.85$

doc percentageOfSubsidies $=$ Proportion of diversification investment coverage .

unit percentageOfSubsidies $=\mathrm{dmnl}$

const ratioOfClosing $=0.02$

doc ratioOfClosing $=$ Average yearly closing of farms in Slovenia from 2003 to 2016 is $2 \%$.

unit ratioOfClosing $=\mathrm{dmnl}$

const yearlyGrowthOfTourism $=0.08$

doc yearlyGrowthOfTourism $=$ Average yearly growth of tourism in Slovenia from 2010 to 2018 is $8 \%$.

unit yearlyGrowthOfTourism $=\mathrm{dmnl}$

spec start $=0.00000$

spec stop $=50.00000$

spec $d t=1.00000$

spec method $=$ Euler (fixed step) 